\title{
Coronary Artery Atherosclerosis Assessment Using Multi Detector Computed Tomography and its Correlation with Framingham Risk Score Among Symptomatic Patients with Chest Pain
}

\author{
HUSSAM EZZAT, M.Sc.*; ISLAM SHAWKY, M.D.**; AHMED FAHMY, M.D.** and \\ AHMED MAGDY, M.D.*** \\ The Departments of Cardiology, Suez Canal Authority Hospital, Port Said*, Faculty of Medicine, Al-Azhar University** and \\ Kobry El-Kobba Military Hospital***, Cairo, Egypt
}

\begin{abstract}
Background: A non-invasive assessment of coronary atherosclerosis by means of Framingham risk scoring (FRS) and multi-slice computed tomography coronary angiography (MSCT) could improve patients' risk stratification. However, the data is still limited on the strong association between FRS and imaging modality in the form of MSCT coronary angiography.
\end{abstract}

Aim of Work: To study the relationship between the extent of atherosclerotic affection among symptomatic patients with chest pain assessed by MDCT \& the CAD risk as assessed by FRS.

Patients and Methods: This prospective cross sectional study took place between September 2017 and September 2018, at Kobry El-Kobba Military Hospital, and enrolled 150 patients who presented with chest pain. All patients were subjected to clinical assessment with FRS, after which they had undergone MDCT coronary angiography to diagnose the type of vessels affected, number of stenotic segments, as well as the volume of plaques obstructing the vessels.

Results: Most of our studied patients were males $(70.7 \%)$ with mean \pm SD age $54.9 \pm 9.1$ years. The mean \pm SD FRS score was $15.6 \pm 11.3$ with median value of 13.2 . The majority of the patients were classified as low risk score. The patients with higher FRS showed more than 2 segments of stenosis and correlated strongly with the number of affected segments as well as the volume of detected plaques. Subjects who were in the higher risk group were significantly older, had disturbed lipid profile and showed the highest systolic blood pressure compared to the low and intermediate risk groups.

Conclusion: Framingham risk score is a well validated clinical score being moderately correlated with number of affected segments and volume of plagues detected in MDCT coronary angiography. Higher group of FRS was significantly associated with male gender, older subjects and disturbed lipid profile.

Key Words: Coronary artery disease - Atherosclerosis - Multi detector computed tomography - MSCT - Framingham risk score - Chest pain - Coronary angiography.

Correspondence to: Dr. Hussam Ezzat,

E-Mail: $\underline{\text { Hussam.ezzat.eg@gmail.com }}$

\section{Introduction}

CORONARY artery disease (CAD) is considered one of the most serious causes of mortality and morbidity. It affects about 16.5 million American over the age of 20 years old. Vascular injury with cholesterol plaque had been established to be the most common cause of CAD, known atherosclerosis. Obstructing blood flow of the great coronary vessels could lead to group of diseases that includes stable and unstable angina, myocardial infarction and sudden cardiac arrest [1]. Patients with any of previously mentioned diseases are commonly presenting with chest pain and/or chest discomfort [2].

Identifying those patients with atherosclerosis who are at risk of acute cardiovascular events, including myocardial infarction (MI) and death, is crucial for the indication of treatment and measures for secondary prevention [3]

A widely used risk score, the Framingham risk score (FRS), which is a reliable tool for prediction of CAD severity, however it doesn't possess higher sensitivity and specificity that don't exceed $70 \%$ and $82 \%$ respectively [4]. Several predictors are included in the FRS: Age, gender, TC, HDL-c, blood pressure, antihypertensive therapy, and cigarette smoking [4].

Computed tomography (CT) coronary angiography is a promising noninvasive imaging modality for diagnosis coronary artery stenosis which showed comparable results to conventional angiography. It has consistently showed to have a very high negative predictive value (well above 90\%) in ruling out patients with significant $\mathrm{CAD}$ defined as coronary luminal stenosis of $>50 \%$ [5] . Introducing the multi-slice computed tomography 
(MSCT) technology such as 64-slice, 128-slice, 256-slice, and 320-slice MSCT has gaining much popularity nowadays with better diagnostic accuracy of CT coronary angiography [6]

The present study was designed to assess the relationship between FRS and MDCT coronary angiography in the diagnosis of CAD.

\section{Patients and Methods}

This work was accepted by the Ethical Committee of Al-Azhar University. After explaining the whole steps, aim and beneficial goals of the study as well as the inconvenience which might be caused by our methodology, written informed consent was obtained from every subject who participated in this research.

We had enrolled 150 patients presented with chest pain to Kobry El-Kobba Military Hospital, Cairo, Egypt between September 2017 and September 2018. All patients were subjected to clinical assessment with FRS, after which they had undergone MDCT coronary angiography owing to diagnosing the type of vessels affected, number of stenoticsegments as well as the volume of plaques obstructing the vessels.

All studied group had been subjected to the following:

- Detailed history including socio-demographic data collection, and economic status were evaluated by questionnaire.

- Clinical general and cardiac examination.

- Laboratory investigations including lipid profile.

- FRS was calculated according to (D'Agostino et al., 2008) [7]. Classification of patients according to their FRS grade:

- Low is $>10 \%$.

- Intermediate is $10-20 \%$.

- High is $>20 \% 10$-year risk of CAD.

- MDCT coronary angiography using 128 -slicesecond-generation dual-source CT scanner: Assessment for coronary vessels stenotic branches, plaque distribution, and plaque volume [8]:

1-Patient preparation:Patients were instructed to fast for about 8 hours, received beta blocker dose and sublingual nitrates.

2- Patients were asked to hold breath during imaging maneuver with reassurance for any side effects of the contrast used.

\section{Statistical analysis:}

Data were analyzed by the Statistical Package for Social Science (IBM SPSS) version 20. Qualitative variables were expressed as number and percentages while quantitative variables were presented as mean, standard deviations. Chi-square test and/or Fisher exact test was used to compare between two groups with qualitative data. The comparison between two groups with quantitative data was done by using student $t$-test for if variable was normally distributed and Mann Whitney test if not normally distributed. Correlation between two quantitative parameters was assessed by Pearson correlation while correlations between qualitative data were assessed by spearman's rho. The $p$-value was considered significant if $p<0.05$.

\section{Results}

Most of our studied patients were males (70.7\%) with Mean \pm SD age 54.9 \pm 9.1 years. Hypertensive patients accounted for 55.3\% of total studied cases, of whom $46 \%$ were smokers. Clinical assessment of the subjects following application of FRS revealed that the Mean \pm SD score was $15.6 \pm 11.3$ with median value of 13.2 and it was ranged between 1-66.6. The majority of the patients were classified as low risk score.

After patients had been subjected to MDCT coronary angiography, 93.3\% showed LAD affection, and the majority of the studied cases were complaining of 1 segment affection (70.7\%). Mean \pm SD volume of plaques detected among the patients was $47.8 \pm 59.2 \mathrm{~mm}$ with $430 \mathrm{~mm}$ being the highest detected value.

Relationship between FRS grades and number of affected segments revealed that patients with higher risk grade showed more than 2 segments of stenosis. FRS has been correlated strongly with the number of affected segments as well as the volume of detected plaques (Tables 5,6).

Subjects who were in the higher risk group were significantly older, had disturbed lipid profile and showed the highest systolic blood pressure compared to the low and intermediate risk groups.

Plaques' volume showed significant positive correlation with cholesterol level and systolic blood pressure and negative association with HDL. Interestingly the patients with 3 and 4 segments affection showed the most higher plaques' volume. 
Table (1): Demographic data, history of comorbidities, type of vessel and number of affected segments using MDCT coronary angiography among studied group.

\begin{tabular}{llc}
\hline & \multicolumn{2}{c}{ Study group } \\
& $\mathrm{N}=150$ patients \\
\hline Age (years): & \multicolumn{2}{c}{$54,93 \pm 9.11$} \\
$\quad$ Mean \pm SD & \multicolumn{2}{c}{56} \\
$\quad$ Median & 35 & 75 \\
$\quad$ Range & \multicolumn{2}{c}{} \\
Gender: & 106 & $70,7 \%$ \\
$\quad$ Male & 44 & $29,3 \%$ \\
Female & 83 & $55,3 \%$ \\
HTN & 69 & $46 \%$ \\
Smoking & \multicolumn{2}{c}{} \\
Type of vessel affected: & 10 & $6,7 \%$ \\
LM & 140 & $93,3 \%$ \\
LAD & 32 & $21,3 \%$ \\
LCX & 25 & $16,7 \%$ \\
RCA & \multicolumn{2}{c}{} \\
Number of the affected segments: & 106 & $70,7 \%$ \\
One & 31 & $20,7 \%$ \\
Two & 12 & $8,0 \%$ \\
Three & 1 & $0,7 \%$ \\
Four & & \\
\hline
\end{tabular}

Table (5): Relationship between FRS grades and number of affected segments.

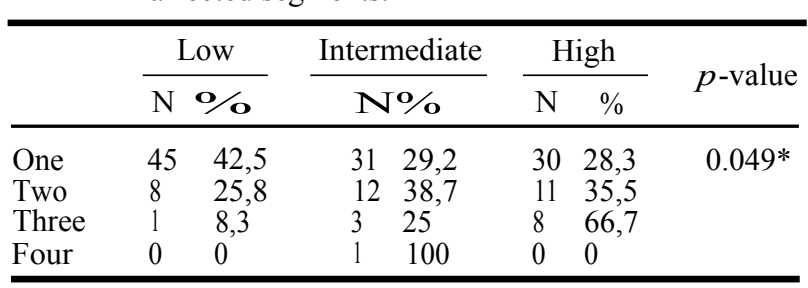

Fischer exact test. $\quad *$ : Statistically significant difference.
Table (2): Clinical and laboratory characteristics among studied group.

\begin{tabular}{llllll}
\hline & \multicolumn{5}{c}{ Study group N=150 patients } \\
\hline & Mean & \pm SD & Median & Range \\
\hline $\begin{array}{c}\text { Systolic blood pressure } \\
(\mathrm{mmHg})\end{array}$ & 121,86 & 12,56 & 122.50 & 100 & 155 \\
$\begin{array}{l}\text { HDL (mg/dl) } \\
\text { Total cholesterol } \\
(\mathrm{mg} / \mathrm{dl})\end{array}$ & 48.97 & 14,59 & 51 & 19 & 80 \\
\hline
\end{tabular}

Table (3): Framingham risk score among studied group.

\begin{tabular}{lccccc}
\hline & \multicolumn{5}{c}{ Study group N=150 patients } \\
\hline & Mean & \pm SD & Median & Range \\
\hline FRS & 15,62 & 11,36 & 13.2 & 1.00 & 66.60 \\
Grades: & & & & & \\
$\quad$ Low & 54 & $36,0 \%$ & & & \\
Intermediate & 47 & $31,3 \%$ & & & \\
$\quad$ High & 49 & $32,7 \%$ & & & \\
\hline
\end{tabular}

Table (4): The volume of plaques among studied group.

\begin{tabular}{ccccc}
\hline & \multicolumn{4}{c}{ Study group $\mathrm{N}=150$ patients } \\
\hline & Mean & $\pm \mathrm{SD}$ & Median & Range \\
\hline Volume & 47.86 & 59.24 & 30 & 10.00430 .00 \\
\hline
\end{tabular}

Table (6): Correlation of FRS value with number of affected segments and volume of plagues.

\begin{tabular}{lcc}
\hline & \multicolumn{2}{c}{ FRS value } \\
\cline { 2 - 3 } & $r$ & $p$ \\
\hline Number of affected segments &, 251 &, $002^{*}$ \\
Volume of plagues &, 235 &, $004^{*}$ \\
\hline
\end{tabular}

Pearson correlation - Spearman rank correlation.

*: Statistically significant difference.

Table (7): The relationship of FRS grades and clinical, laboratory and volume of plaques.

\begin{tabular}{|c|c|c|c|c|c|c|c|}
\hline & \multicolumn{2}{|c|}{ Low } & \multicolumn{2}{|c|}{ Moderate } & \multicolumn{2}{|c|}{ High } & \multirow{2}{*}{$p$-value } \\
\hline & Mean & 士 $\mathrm{SD}$ & Mean & $\pm \mathrm{SD}$ & Mean & $\pm \mathrm{SD}$ & \\
\hline Age (years) & 52,53 & 9,19 & 54,19 & 8,51 & 58,28 & 8,75 & $0,010^{*}$ \\
\hline T. cholesterol (mg/dl) & 182,07 & 52,94 & 217,27 & 64,32 & 250,16 & 68,79 & $0,000^{*}$ \\
\hline $\mathrm{HDL}(\mathrm{mg} / \mathrm{dl})$ & 55,79 & 12,05 & 49,87 & 15,42 & 40,59 & 12,17 & $0,000^{*}$ \\
\hline Systolic blood pressure $(\mathrm{mmHg})$ & 116,11 & 10,40 & 121,38 & 12,05 & 128,67 & 12,10 & $0,000^{*}$ \\
\hline Volume $(\mathrm{mm})$ & 38,518 & 42,17 & 44,25 & 41,27 & 61,63 & 83,62 & $0.012 *$ \\
\hline
\end{tabular}

1 way Anova - Kruskalwallistest. *: Statistically significant difference.

Table (8): Correlation of volume of plaques with clinical, laboratory data.

\begin{tabular}{llc}
\hline & \multicolumn{2}{c}{ Volume of plaques } \\
\cline { 2 - 3 } & \multicolumn{1}{c}{$r$} & $p$ \\
\hline Age & -0.006 & $0.943 \mathrm{NS}$ \\
Cholesterol &, 335 & $0,000^{*}$ \\
HDL & -0.232 & $0.004^{*}$ \\
Systolic blood pressure & 0.286 & $0.001^{*}$ \\
\hline Pearson correlation - Spearman correlation. & & \\
*: Statistically significant difference. & & \\
NS: No statistically significant difference. & &
\end{tabular}


Table (9): Relation between volume of plaques and number of affected segments.

\begin{tabular}{|c|c|c|c|c|c|c|c|c|c|}
\hline & \multicolumn{2}{|c|}{$\begin{array}{c}\text { One } \mathrm{N}=106 \\
\text { patients }\end{array}$} & \multicolumn{2}{|c|}{$\begin{array}{c}\text { Two N=31 } \\
\text { patients }\end{array}$} & \multicolumn{2}{|c|}{$\begin{array}{c}\text { Three } \mathrm{N}=12 \\
\text { patients }\end{array}$} & \multicolumn{2}{|c|}{$\begin{array}{c}\text { Four } \mathrm{N}=1 \\
\text { patient }\end{array}$} & \multirow{2}{*}{$p$-value } \\
\hline & Mean & $\pm \mathrm{SD}$ & Mean & $\pm \mathrm{SD}$ & Mean & $\pm \mathrm{SD}$ & Mean & $\pm \mathrm{SD}$ & \\
\hline Volume (mm) & 39,52 & 50.18 & 62.90 & 79.17 & 85.83 & 58.22 & 100.00 & 0 & $0.000 *$ \\
\hline
\end{tabular}

\section{Discussion}

Precise identification of patients who are at risk for CAD is very crucial owing to reduce morbidity and mortality among those individuals. In order to accurately identify those patients; FRS, one of the most well-known clinical risk scores is being used in clinical practice. However, its moderate or limited predictive value highlights the potential utility of direct imaging modalities as MSCT coronary angiography for proper diagnosis of coronary atherosclerosis [9]

A Turkish report studied this association and showed variable results compared to ours as the prevalence of hyperlipidemia, hypertension, and smoking was 66, 64, and $31 \%$, respectively. [10], while other reports showed relatively lower prevalence $56.5,51.2$, and 28.2 ; and 56, 24, and $23 \%$, respectively $[11,12]$.

Among our studied subjects, mean systolic blood pressure at presentation was within normal range (mean \pm SD $121.8 \pm 12.5 \mathrm{mmHg}$ ), mean \pm SD cholesterol level was higher $215 \pm 67.8 \mathrm{mg} / \mathrm{dl}$ despite mean \pm SD HDL being within protective range $(48.9 \pm 14.5 \mathrm{mg} / \mathrm{dl})$. This could be referred to that cholesterol level showed not too much higher value.

After presentation, FRS was calculated for all selected patients which showed mean score of 15.6 with median level of 13.2. Patients were then classified according to grades of FRS and showed that the low risk group (36\%) being most common and followed in order by high risk group $(32.7 \%)$.

Studying the association between grades of FRS and the type of vessel affected that showed no significant relationship between any of the vessels and those clinical grades. Unlike to our findings, Seaoud et al., showed that there was a significant difference between the three grades of FRS regarding left main ( $p$-value $=0.001)$, LAD ( $p$-value 0.011$)$ and RCA ( $p$-value 0.013) [9]

Multivariate logistic regression was done for acquiring the predictors of volume of plaques, it was revealed that FRS, cholesterol level, HDL and systolic blood pressure were the predictors associated with higher volume. The predictors showed also positive significant correlations of plaques' volume. Jong-Shiuan, et al., reported that only FRS and CACS were the only predictors of atherosclerotic plaque in the studied patients and neither cholesterol level nor body mass index were predictors of the plaques [13]

In the study by $\mathrm{Ug}$ ur et al., which studied the association between cardiovascular (CV) risk factors and coronary atherosclerotic plaque (CAP) burden/subtypes shown by multidetector computed tomography in symptomatic patients free of known CAD. It had reported that male subjects, older age, hypertension, diabetes mellitus, smoking, and dyslipidemia had increased the likelihood of the presence of CAP in univariate analysis $(p<0.001)$. It was demonstrated also that older age, male sex, dyslipidemia, and diabetes mellitus independently increased the likelihood of the presence of CAP in multivariate analysis $(p<0.005)$. Patients with low FRS showed a large number of CAPs (33.8 and $40.4 \%$ ), although CAP was more prevalent in the high-risk groups (67 and 78\%, respectively) [10].

All numbers of affected segments were compared regarding different grades of Framingham risk score. This comparison showed that the more number of affected segments, the higher grade of FRS with significant difference. Most of patients who showed 1 segment affection showed were categorized as low FRS, while most of the patients with 3 segments had been categorized as higher FRS. The only patient who showed 4 segments affection was classified as intermediate risk. Therefore, a significant positive correlation was revealed between FRS value and number of affected segments $(p=0.002)$. This was in agreement with Seaoud et al., who showed that number of segments affected seen by $\mathrm{CT}$ was significantly related to Framingham risk score. Patients of low and intermediate grades had mostly one segment affection, while those of higher grade had mostly two segment affection with significant difference between the three grades $(p=0.002)$ [9]

Patients in the higher class of FRS showed the highest mean volume of plaques compared to other classes of FRS ( $p=0.012)$. In the study by Pen et 
al., similar finding was reported as he noted that the mean atherosclerosis plaque burden increased with increasing the 10 -year \% risk as calculated by FRS [14]. Another study demonstrated the same results as they revealed that plaque volume increased with increasing FRS [15]

On the otherhand patients categorized as low FRS class had been younger, with lowest cholesterol level, highest HDL and lowest level of systolic blood pressure compared to the other classes of FRS. Jong-Shiuan and his colleagues reported similar results as he showed that patients with atherosclerotic plaques were older, had higher systolic blood pressure and cholesterol level [13]

Comparing mean values of FRS among gender in the studied patients revealed that male patients had higher significant value compared with females, however male patients with higher FRS don't preclude that they would show higher volume of plaques. Hwang et al.,reported that FRS was effective for predicting coronary artery disease only in symptomatic women [16].

A study in Taiwan demonstrated that the FRS are independent predictor of subclinical coronary atherosclerosis in asymptomatic subjects with low to intermediate cardiovascular risk [13]

Our report has some limitations: First, this is a cross-sectional study in a group of patients with suspected CAD, and the potential role of MDCT to detect CAP cannot be generalized to the whole population to optimize $\mathrm{CV}$ risk reduction strategies. Second, absence of comparative group prevent achieving powerful validity of FRS. Coronary atherosclerosis can be detected in patients with increasing age; therefore, large-scale follow-up studies are needed to clarify the clinical significance of those CAPs in the low-risk patient population. Finally, in contrast to other non-invasive methods, MDCT has a disadvantage in terms of radiation exposure and contrast administration. Although technologies aimed to reduce radiation exposure are evolving, long-term hazardous effects of radiation especially on young women patients should be kept in mind when MDCT-based non-invasive evaluation methods are being considered.

\section{References}

1- WONG N.D.: Epidemiological studies of CHD and the evolution of preventive cardiology. Nat. Rev. Cardiol. May, 11 (5): 276-89, 2014.

2- National Clinical Guideline Centre for Acute and Chronic Conditions (UK). Chest Pain of Recent Onset: Assessment and Diagnosis of Recent Onset Chest Pain or Discomfort of Suspected Cardiac Origin. London: Royal College of Physicians (UK); Mar. (NICE Clinical Guidelines, No. 95) 4, People Presenting with Acute Chest Pain Chapter, 2010.

3- CESAR L.A., FERREIRA J.F., ARMAGANIJAN D., GOWDAK L.H., MANSUR A.P., BODANESE L.C., et al. Guideline for stable coronary artery disease. Arq. Bras. Cardiol., 103 (2): 01-59, 2014.

4- LAKIC' D., BOGAVAC-STANOJEVIC' N., JELIC'IVANOVIC Z., KOTUR-STEVULJEVIC' J, SPASIC' S and KOS M.: A multimarker Approach for the Prediction of Coronary Artery Disease: Cost-Effectiveness Analysis Value Health Sep., 13 (6): 770-7, 2010.

5- ZOU K.H., O'MALLEY A.J. and MAURI L.: Receiveroperating characteristic analysis for evaluating diagnostic tests and predictive models. Circulation, 115 (5): 654 $657,2007$.

6- OTERO H.J., STEIGNER M.L. and RYBICKI F.J.: The "Post-64" Era of Coronary CT Angiography: Understanding New Technology from Physical Principles. Radiol. Clin. North. Am. Jan., 47 (1): 79-90, 2009.

7- D'AGOSTINO R.B., VASAN R.S., PENCINA M.J., WOLF P.A., COBAIN M., MASSARO J.M., et al.: General Cardiovascular Risk Profile for Use in Primary Care: The Framingham Heart Study. Circulation. Feb., 12; 117 (6): $743-53,2008$

8- RAFF G.L., CHAIR, ABIDOV A., ACHENBACH S. BERMAN D.S., BOXT L.M., et al.: SCCT guidelines for the interpretation and reporting of coronary computed tomographic angiography. J. Cardiovasc. Comput. Tomogr. Mar., 3 (2): 122-36, 2009.

9- SEAOUD E. and SHAWKY A.: Framingham risk score and extent of atherosclerosis in non-diabetic patients with suspected coronary artery disease. J. Indian. Coll. Cardiol., 8 (1): 18-20, 2018

10- CANPOLAT U., YORGUN H., AYTEMIR K., HAZROLAN T., KAYA E.B., ATES A.H., et al.: Cardiovascular risk and coronary atherosclerotic plaques detected by multidetector computed tomography: Framingham and SCORE risk models underestimate coronary atherosclerosis in the symptomatic low-risk Turkish population. Coron Artery Dis., 23 (3): 195-200, 2012.

11- BAMBERG F., DANNEMANN N., SHAPIRO M.D., SENEVIRATNE S.K., FERENCIK M., BUTLER J., et al.: Association between cardiovascular risk profiles and the presence and extent of different types of coronary atherosclerotic plaque as detected by multidetector computed tomography. Arterioscler. Thromb. Vasc. Biol., 28 (3): 568-574, 2008

12- FALETRA F.F., KLERSY C., D'ANGELI I., PENCO M., PROCACCINI V., PASOTTI E., et al.: Relationship between coronary atherosclerotic plaques and traditional risk factors in people with no history of cardiovascular disease undergoing multi-detector computed coronary angiography. Heart, 2009;

13- YEH J-S., KAO Y-T., LIN F-Y., SHIH C-M., TSAO NW., CHAN C-S., et al.: Combined Framingham risk score and coronary artery calcium score predict subclinical coronary plaque assessed by coronary computed tomog- 
raphy angiogram in asymptomatic Taiwanese population. Acta. Cardiol. Sin., 29 (5): 429, 2013.

14- PEN A., YAM Y., CHEN L., DENNIE C., MCPHERSON R. and CHOW B.J.: Discordance between Framingham Risk Score and atherosclerotic plaque burden. Eur. Heart. J., 34 (14): 1075-1082, 2013.

15- MARSO S.P., FRUTKIN A.D., MEHTA S.K., HOUSE J.A., McCRARY J.R., KLAUSS V., et al.: Intravascular ultrasound measures of coronary atherosclerosis are associated with the Framingham risk score: An analysis from a global IVUS registry. EuroIntervention J. Eur. Collab Work Group Interv. Cardiol. Eur. Soc. Cardiol., 5 (2): 212-218, 2009.

16- HWANG Y., KIM Y., CHUNG I-M., RYU J. and PARK H.: Coronary heart disease risk assessment and characterization of coronary artery disease using coronary CT angiography: Comparison of asymptomatic and symptomatic groups. Clin. Radiol., 65 (8): 601-608, 2010.

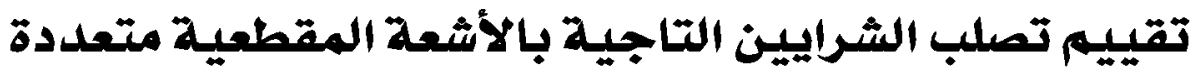

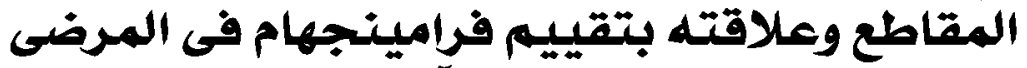 الذين يعانون من آلامئم بالصدر فئمر}

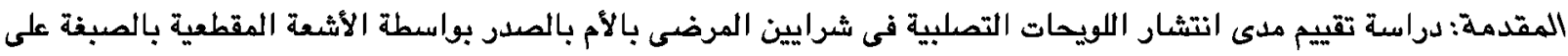

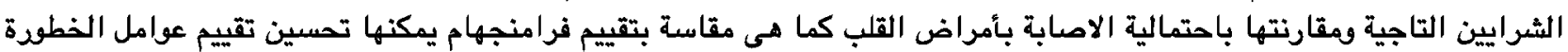

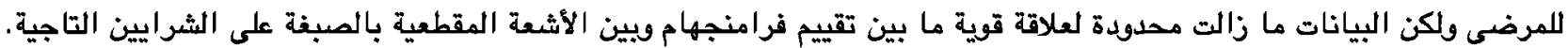

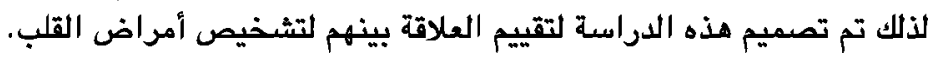

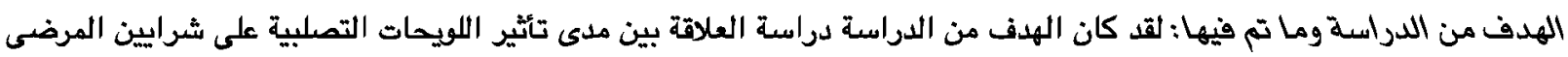

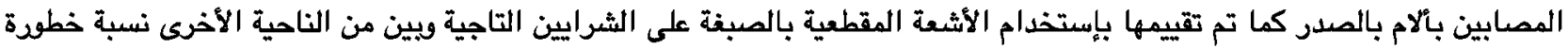

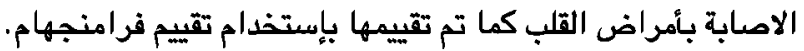

كما شملت الدراسة ــا مريض من الجنسين بمستشفى كوبرى القبة العسكرى مستشفى القلب يعانون من ألام بالصدر وتم طلب عمل

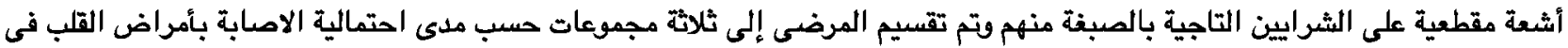

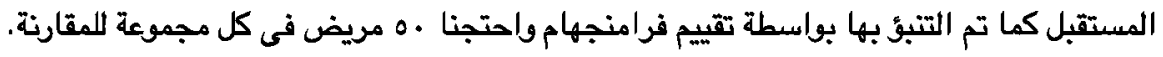

النتائج : أظهرت النتائج أن المرضى فى المجموعة الاكثر خطورة لديهم لويحات تصلبية وضيق فى قسمين من الثَرايين أو أكثر وكانوا

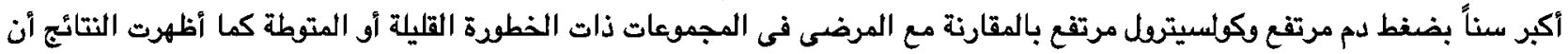

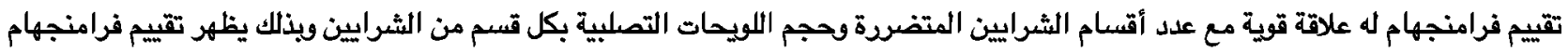
كأداة فعالة لتقييم تصلب الشراين. 